University of Nebraska - Lincoln

DigitalCommons@University of Nebraska - Lincoln

5-8-2006

\title{
Microcantilever Torque Magnetometery Study of Patterned Magnetic Films
}

\author{
L. Yuan \\ University of Nebraska - Lincoln \\ Lei Gao \\ University of Kansas, Igao3@unl.edu \\ Ildar F. Sabiryanov \\ University of Nebraska - Lincoln, isabirianov2@unl.edu \\ Sy-Hwang Liou \\ University of Nebraska-Lincoln, sliou@unl.edu \\ M. D. Chabot \\ University of Nebraska - Lincoln \\ See next page for additional authors
}

Follow this and additional works at: https://digitalcommons.unl.edu/physicsliou

Part of the Physics Commons

Yuan, L.; Gao, Lei; Sabiryanov, Ildar F.; Liou, Sy-Hwang; Chabot, M. D.; Min, D. H.; Moreland, J.; and Han, B., "Microcantilever Torque Magnetometery Study of Patterned Magnetic Films" (2006). Si-Hwang Liou Publications. 95.

https://digitalcommons.unl.edu/physicsliou/95

This Article is brought to you for free and open access by the Research Papers in Physics and Astronomy at DigitalCommons@University of Nebraska - Lincoln. It has been accepted for inclusion in Si-Hwang Liou Publications by an authorized administrator of DigitalCommons@University of Nebraska - Lincoln. 


\section{Authors}

L. Yuan, Lei Gao, Ildar F. Sabiryanov, Sy-Hwang Liou, M. D. Chabot, D. H. Min, J. Moreland, and B. Han 


\section{Microcantilever Torque Magnetometery Study of Patterned Magnetic Films}

Yuan, L.

Gao, L.

Sabirianov, R.

Liou, S. H.

Chabot, M. D.

Min, D. H.

Moreland, J.

Han, B.

Department of Physics and Astronomy and Center for Materials Research and Analysis, University of Nebraska-Lincoln, Lincoln, NE, USA

This paper appears in: Magnetics Conference, 2006. INTERMAG 2006. IEEE International

Publication Date: 8-12 May 2006

Pages: 583 - 583

Location: San Diego, CA, USA

ISBN: 1-4244-1479-2

Digital Object Identifier: 10.1109/INTMAG.2006.376307

Posted online: 2007-06-25 10:08:58.0

Copyright (C) 2006 IEEE. Used by permission. 


\section{FD-01}

\section{Microcantilever Torque Magnetometery Study of Patterned Magnetic Films.}

L. Yuan ${ }^{1}$, L. Gao ${ }^{1}$, R. Sabirianov ${ }^{1}$, S. H. Liou ${ }^{1}$, M. D. Chabot ${ }^{2}$, D. H. Min², J. Moreland ${ }^{3}$ and B. $\mathrm{Han}^{4}$

1. Department of Physics and Astronomy and Center for Materials Research and Analysis, University of Nebraska-Lincoln, Lincoln, NE, USA; 2. Department of Physics, University of San Diego, San Diego, CA, USA; 3. National Institute of Standards and Technology, Boulder, CO, USA; 4. State Key Laboratory of Magnetism, Institute of Physics, Chinese Academy of Sciences, Beijing, Beijing, China

The study of the small, defined magnetic structures has attracted much attention due to interest in both technology applications and fundamental research in micromagnetism. Microcantilever torque magnetometry (MTM) is a promising new experimental technique for measuring such small magnetic features [1]. One of the challenges of using this technique is to place the sample on the cantilever. In this work, we develop a new process for preparing patterned magnetic film on cantilever and show a primarily result of magnetic interactions in a paired magnetic bar measured by MTM. The process of patterning the magnetic film on the cantilever is following: (a) deposit a multilayer $\mathrm{Au}(200 \mathrm{~nm}) / \mathrm{Cr}(10 \mathrm{~nm})$ on cantilever, (b) patterning using a focused ion beam (FIB) milling, (c) magnetic film deposition through a mask, and (d) a lift-off process. Fig. 1 shows an example of the patterned cantilever with 300 dots of $500 \mathrm{~nm}$ in diameter using this process.

In order to understand the magnetic interaction between a pair of bars, we prepare a sample as shown in Fig. 2. A $7 \mu \mathrm{m} \times 7 \mu \mathrm{m} \times 30 \mathrm{~nm}$ Ni80Fe20 film was put on the top left corner of the MTM cantilever. The Ni80Fe 20 film was then patterned by a FIB workstation into two single $7 \mu \mathrm{m} \times 3.5$ $\mu \mathrm{m} \times 30 \mathrm{~nm}$ bars by cutting a $50 \mathrm{~nm}$ gap in the center of the film [Fig. 2(a)]. After the measurement, the top bar was removed with FIB milling and just left a single $7 \mu \mathrm{m} \times 3.5 \mu \mathrm{m} \times 30 \mathrm{~nm}$ bar on the cantilever [Fig. 2(b)].

Magnetic properties of the patterned Ni80Fe20 films were characterized using a MTM at room temperature and in air. All measurements were done with a magnetic field applied in plane and perpendicular to the axis of the cantilever, as marked in the top of Fig. 2(a). Fig. 3 shows the magnetic hysteresis loops for the single and paired $7 \mu \mathrm{m} \times 3.5 \mu \mathrm{m} \times 30 \mathrm{~nm}$ Ni80Fe20 bars. For the single bar, the magnetization reversal occurs around the coercivity field of $-1.23 \mathrm{kA} / \mathrm{m}$. It is correlated to the domain wall propagation quickly through the bar. The smaller change in magnetization at - 4 $\mathrm{kA} / \mathrm{m}$ may be caused by the annihilation of the small domain structure at the edge of the film. For paired bars, the magnetization reversal occurs at $-1.3 \mathrm{kA} / \mathrm{m}$ and $-1.7 \mathrm{kA} / \mathrm{m}$. The first jump at a field of $-1.3 \mathrm{kA} / \mathrm{m}$ corresponds to the reversal of one of the paired bars. The second jump at a field of $1.7 \mathrm{kA} / \mathrm{m}$ corresponds to the reversal of the other one. The fact that the switching field of single bars is larger than the reversing field of only one of the paired bars and less than that of both paired bars indicates magnetostatic interaction exists between the closely paired bars and that consists with micromagnetic simulations.

In summary, we develop a process to pattern the magnetic film on the MTM cantilever. And by using MTM, we can study the magnetic interaction between the closed small sized and shapeddefined magnetic elements with high resolution. [1] M. D. Chabot, J. Moreland, L. Gao, S. H. Liou and C. W. Miller, Journal of Microelectromechanical systems, 14, 1118 (2005).
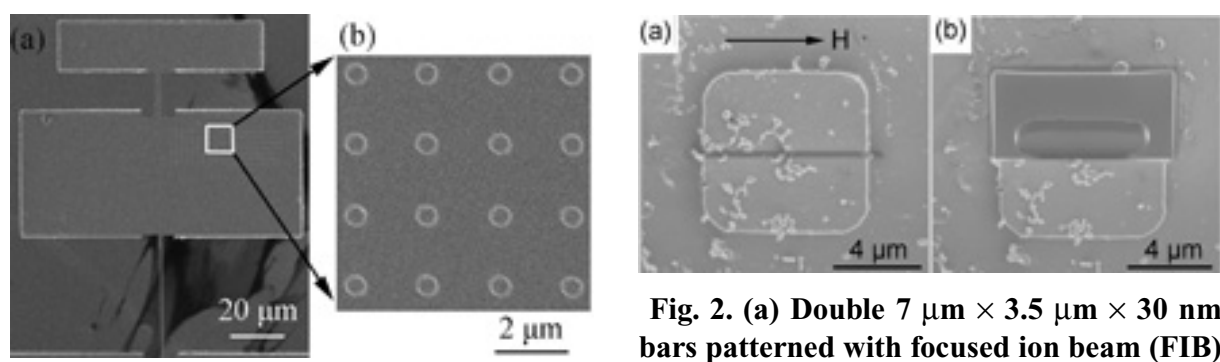

Fig. 2. (a) Double $7 \mu \mathrm{m} \times 3.5 \mu \mathrm{m} \times 30 \mathrm{~nm}$ bars patterned with focused ion beam (FIB) on the $7 \mu \mathbf{m} \times 7 \mu \mathbf{m} \times 30 \mathbf{n m}$ Ni80Fe20 film with a gap of $50 \mathrm{~nm}$ between adjacent bars. (b) Single $7 \mu \mathrm{m} \times 3.5 \mu \mathrm{m} \times 30 \mathrm{~nm}$ bar after removing the top bar with FIB.
Fig. 1 Nanofabricated the cantilever with 300 dots with diameter of $500 \mathrm{~nm}$. (a) The SEM picture of the cantilever and (b) the enlarged SEM pictures of the patterned circle dots on the cantilever.

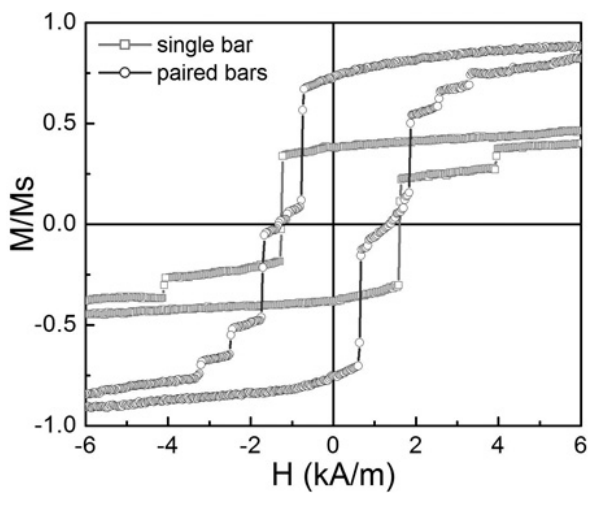

Fig. 3. Magnetic hysteresis loops of the single $7 \mu \mathrm{m} \times 3.5 \mu \mathrm{m} \times 30 \mathrm{~nm}$ Ni80Fe20 bar and same size paired bars with a gap of $50 \mathrm{~nm}$ obtained with a microcantilever torque magnetometer. 